\title{
Out-of-pocket expenditure in accessing healthcare services among Chronic Kidney Disease patients in Anuradhapura District
}

\author{
S J Senanayake ${ }^{1}$, N S Gunawardena ${ }^{2}$, P Palihawadana ${ }^{3}$, S Bandara ${ }^{4}$, P Bandara ${ }^{5}$, A U Ranasinghe ${ }^{5}$, \\ R H Karunarathna ${ }^{5}$, G P Kumara ${ }^{5}$
}

(Index words: chronic kidney disease, Anuradhapura, cost)

\begin{abstract}
Introduction Chronic Kidney Disease (CKD) has significant economic impact on both patients' households and the country.

Objectives To assess the out-of-pocket (OOP) expenditure of accessing health services among CKD patients in Anuradhapura District

Methods This community based cross-sectional study included a representative sample of 1174 registered CKD patients from all 19 Medical Officer of Health areas in the District of Anuradhapura. Trained para-medical staff visited the households and administered an interviewer administered questionnaire to gather information.
\end{abstract}

Results A total of 1118 CKD patients participated. Mean age was 58.3 (SD 10.8) years. Fifty nine (5.3\%) patients had been hospitalized during the six months preceding data collection. The total OOP for a hospital admission for one patient was Rs. 3625 (IQR 1650-8760). Thirty eight (3.4\%) patients were on dialysis. The median direct cost per patient for an episode of dialysis was Rs.595 (IQR 415-995) while the median direct cost for a dialysis patient per month was Rs.5490 (IQR 3950-10934). In the study population a total of $1095(98.0 \%)$ had attended clinic at least once during the six months preceding the study. The OOP expenditure for a single clinic visit for one patient was Rs.434 (IQR 200860).

Conclusions CKD patients living in the Anuradhapura District spent significant amounts on accessing health care which can worsen their economic hardships. Planned interventions are warranted in order to improve their quality of life and financial situation.

Ceylon Medical Journal 2017; 62: 100-103

DOI: http://doi.org/10.4038/cmj.v62i2.8475

\section{Introduction}

Incidence and prevalence of chronic kidney disease (CKD) is increasing globally and contributes significantly to deaths and disability (1). During the past $10-15$ years several districts in Sri Lanka have been affected by the rapid increase in CKD of unknown origin. Anuradhapura District has the highest CKD burden in Sri Lanka at present [2].

CKD has a big impact on the financial status of the patient [3]. Disability, work loss and out-of-pocket expenditure have adverse impact not only on the socioeconomic status of patients and their families but also on their psychological wellbeing.

Rs. 800 million was allocated for the kidney disease programme and another Rs. 500 million was allocated for non-communicable diseases including kidney disease in the 2016 national budget. Further, Rs. 1647 million has been allocated for a monthly allowance of Rs. 3000 for patients with CKD [4].

Even though the government spends a significant amount of money on CKD patients and most healthcare services are provided free of charge, these patients probably incur significant amount of out-of-pocket expenditure. This has not been studied adequately in Sri Lanka. The cost incurred by a patient can be broadly divided into direct and indirect costs. Direct cost is the cost of accessing health services. This include cost such as those of travel, medication and investigations. The indirect cost is the income lost due to illness or while seeking or receiving treatment [5].

The income loss of patients with CKDu has not been studied previously. Identifying these costs will enable health care providers and the Social Services to formulate interventions which can improve the wellbeing of these

${ }^{1}$ Family Health Bureau, Sri Lanka, ${ }^{2}$ Faculty of Medicine, University of Colombo, Sri Lanka, ${ }^{3}$ Epidemiology Unit, Ministry of Health, Sri Lanka, ${ }^{4}$ Institute of Policy Studies, ${ }^{5}$ Colombo, Sri Lanka, North Central Provincial Directors Office, Anuradhapura, Sri Lanka.

Correspondence: SJS, e-mail: <sjsenanayake@yahoo.com>. Received 6 October 2016 and revised version accepted 14 February 2017.

This is an open-access article distributed under the terms of the Creative Commons Attribution License, which permits unrestricted use, distribution, and reproduction in any medium, provided the original author and source are credited. 
patients. The main aim of this study was to assess the out-of-pocket expenditure in accessing health services among CKD patients in Anuradhapura District.

\section{Methods}

\section{Selection of study sample}

A population based descriptive cross-sectional study was conducted in the District of Anuradhapura in the North Central Province (NCP) of Sri Lanka. The study population consisted of patients diagnosed with CKD aged $>18$ years, living in the Anuradhapura District. Diagnosis was confirmed using clinical records. An appropriate sample size calculation equation was used and the required sample size was 1174.

The study was conducted in all 19 Medical Officer of Health $(\mathrm{MOH})$ areas of the Anuradhapura District. The number of patients included from each $\mathrm{MOH}$ area was proportionate to the number of CKD patients registered in each of the $\mathrm{MOH}$ areas. The required number of patients from each $\mathrm{MOH}$ area was selected using simple random sampling. The population based CKD register for each $\mathrm{MOH}$ area available at the office of Provincial Director of Health Services, was used as the sampling frame.

\section{Assessment of out-of-pocket expenditure}

A questionnaire was developed by reviewing literature and from inputs obtained from CKD patients and carers. This questionnaire was pre-tested. Total OOP expenditure borne by the patient was calculated by assessing the following. Expenditure incurred for hospital admissions, dialysis and clinic visits which included cost of transport, food, drugs, investigations, medical equipment and expenses for accompanying person. Expenditure on private medical consultations for treatment by a Western medical practitioner, Ayurvedic medical practitioner or any other type of medical practitioner and expenditure on religious rituals were also included.

\section{Data collection}

Trained Public Health Inspectors visited the households and administered the questionnaire to assess the cost incurred by each patient. Eligibility of the selected study participants was assessed by the data collectors and if found eligible they were informed about the purpose of the study and were invited to participate in the study. Measures were taken to ensure the quality of information gathered while collecting data. Data was obtained from the patients and from family members if the patient was unaware of the costs incurred. Information was cross checked with documentary data such as bills and bank statements when available.

The study was approved by the Ethics Review Committee of the Faculty of Medicine, University of Colombo.

\section{Statistical analysis}

Mean or median and standard deviation or interquartile range (IQR) were used to summarize the data. Statistical analysis was done using SPSS version 20.0.

\section{Results}

\section{Patient characteristics}

Of the 1174 patients selected to be included in the study 56 (4.8\%) did not participate giving a response rate of $95.2 \%$. The mean age of the study population was 58.4 years (SD 10.8). There was a preponderance of males $(\mathrm{n}=701 ; 62.7 \%)$. The mean estimated glomerular filtration rate (eGFR) of the sample was 31.8 (SD 20.2) $\mathrm{ml} / \mathrm{min} / 1.73 \mathrm{~m}^{2}$. The mean number of years since diagnosis with CKD was 4.1 (SD 3.2) years. Of the sample 38 (3.4\%) were on haemodialysis.

\section{Economic profile of the patients}

Majority of the participants were previously employed ( $n=567 ; 50.7 \%)$, while 387 (34.6\%) were currently employed. Hundred and sixty four (14.7\%) had never been employed. The monthly family income of approximately half $(n=527 ; 47.1 \%)$ the study population was between Rs. 5000-20,000. A personal monthly income of $<$ Rs. 5000 was reported by $64.0 \%$. Two hundred and fifty eight females (61.9\%) and 328 (46.8\%) males had a monthly personal of Rs. 2000-5000.

\section{Out-of-pocket expenditure of a hospital admission}

Fifty nine (5.3\%) patients had been admitted to hospital during the six months preceding data collection. Mean duration of hospital stay was $5.8(\mathrm{SD}=3.2)$ days (median $=7$ ). Table 1 shows the cost of the last hospital admission in patients who had at least one hospital admission during the last six months. Total OOP expenditure of a hospital admission was Rs. 3625 (IQR 1650-8760). The highest proportion of cost (62.0\%) was the cost of visiting the patient in hospital by immediate family members. The proportion spent on transport was $14.6 \%$ and food $10.9 \%$.

\section{Out-of-pocket expenditure of a dialysis episode}

Thirty eight (3.4\%) patients were undergoing haemodialysis, at the time of the study. The mean duration since commencing of dialysis was $1.7(\mathrm{SD}=1.6)$ years. Table 2 shows the cost of the last dialysis episode. The total OOP expenditure for a single dialysis episode was Rs. 595 (IQR 415-995). The main OOP expenditure of an episode of dialysis was for transport (42.7\%) food (22.2\%) and drugs (20.8\%).

\section{Out-of-pocket expenditure of a clinic visit}

Almost all ( $n=1095 ; 98.0 \%)$ had attended clinic at least once during the previous six months. Of them 1075 
Table 1. Out -of-pocket expenditure incurred during the last hospital admission

\begin{tabular}{|c|c|c|}
\hline Costing element & $\begin{array}{l}\text { Number }(\%) \\
(N=59)\end{array}$ & $\begin{array}{l}\text { Out-of -pocket } \\
\text { expenditure } \\
\text { (SLR)Median (IQR) }\end{array}$ \\
\hline \multicolumn{3}{|l|}{ Transport } \\
\hline To come to the hospital & $59(100.0)$ & $150(55-500)$ \\
\hline To go home & $56(94.9)$ & $200(55-482.5)$ \\
\hline Total & $59(100.0)$ & $300(110-1000)$ \\
\hline \multicolumn{3}{|l|}{$\begin{array}{l}\text { Bystander during } \\
\text { hospital stay }\end{array}$} \\
\hline Salary & $2(3.4)$ & 18500 \\
\hline Transport & $10(16.9)$ & $150(132.5-212.5)$ \\
\hline Food & $11(18.6)$ & $300(200-500)$ \\
\hline Other & $0(0.0)$ & 0 \\
\hline Total & $14(23.7)$ & $400(200-957.5)$ \\
\hline \multicolumn{3}{|l|}{ Other expenses } \\
\hline Drugs & 20 (33.9) & $1000(500-2000)$ \\
\hline Investigations & 11 (18.6) & $1200(850-3000)$ \\
\hline Medical instruments & $01(1.7)$ & $80(80-80)$ \\
\hline Food & 33 (55.9) & $700(250-2250)$ \\
\hline Other & $02(3.4)$ & 1250 \\
\hline Total & $45(76.3)$ & $1100(400-3250)$ \\
\hline \multicolumn{3}{|l|}{$\begin{array}{l}\text { Accompanying person } \\
\text { during traveling }\end{array}$} \\
\hline Payment & $0(0.0)$ & \\
\hline Transport & $21(35.6)$ & $80(55-140)$ \\
\hline Food & $10(16.9)$ & $350(200-450)$ \\
\hline Other & $01(1.7)$ & $200(200-200)$ \\
\hline Total & $30(50.8)$ & $140(67.5-325)$ \\
\hline $\begin{array}{l}\text { Hospital visits by } \\
\text { immediate family }\end{array}$ & 58 (98.3) & $1500(600-3525)$ \\
\hline $\begin{array}{l}\text { Hospital Bills } \\
\text { (Private Hospital) }\end{array}$ & $01(1.7)$ & 64168.39 \\
\hline $\begin{array}{l}\text { Total OOP of a } \\
\text { hospital admission }\end{array}$ & $59(100.0)$ & $3625(1650-8760)$ \\
\hline
\end{tabular}

Table 2. Out-of-pocket expenditure of an episode of dialysis

\begin{tabular}{|c|c|c|}
\hline Costing element & $\begin{array}{l}\text { Number }(\%) \\
(N=38)\end{array}$ & $\begin{array}{l}\text { (Out-of-pocket } \\
\text { expenditure } \\
(S L R)\end{array}$ \\
\hline \multicolumn{3}{|l|}{ Transport } \\
\hline To get to the hospital & 34 (89.5) & $160(100-250)$ \\
\hline To go home & $35(92.1)$ & $160(100-250)$ \\
\hline \multicolumn{3}{|l|}{ Other expenses } \\
\hline Drugs & 04 (10.5) & $350(200-475)$ \\
\hline Investigations & $0(0.0)$ & 0 \\
\hline Medical instruments & $0(0.0)$ & 0 \\
\hline Food & $24(63.2)$ & $250(162.5-500.0)$ \\
\hline Other & 03 (7.9) & $200(200-200)$ \\
\hline \multicolumn{3}{|l|}{$\begin{array}{l}\text { Accompanying person } \\
\text { during traveling }\end{array}$} \\
\hline Payment & $0(0.0)$ & 0 \\
\hline Transport & $18(47.4)$ & $155(120-210)$ \\
\hline Food & 04 (10.5) & $200(125-275)$ \\
\hline Total & & $160(120-300)$ \\
\hline $\begin{array}{l}\text { Total OOP for a } \\
\text { dialysis episode }\end{array}$ & $36(94.7)$ & 595 (415-995) \\
\hline
\end{tabular}

(96.1\%) had attended a government clinic in Anuradhapura or an adjacent district, 09 (0.8\%) had attended a private clinic, $03(0.3 \%)$ had attended an Ayurveda clinic and $08(0.7 \%)$ had attended a clinic in Galle, Kandy or Colombo. Details of the costing elements were gathered for the last such clinic visit. The total OOP expenditure of the last clinic visit was Rs. 434
Table 3. Out- of-pocket expenditure for a clinic visit

\begin{tabular}{|c|c|c|}
\hline Costing element & $\begin{array}{l}\text { Number }(\%) \\
(N=1075)\end{array}$ & $\begin{array}{l}\text { (Rs.) Median } \\
\text { (IQR) }\end{array}$ \\
\hline \multicolumn{3}{|l|}{ Transport } \\
\hline To come to the hospital & $1075(100.0)$ & $50(30-100)$ \\
\hline To go home & $1035(96.3)$ & $50(30-100)$ \\
\hline Total & & $100(60-200)$ \\
\hline \multicolumn{3}{|l|}{ Other expenses } \\
\hline Drugs & $431(40.1)$ & $460(300-800)$ \\
\hline Investigations & $76(7.1)$ & $815(252-1300)$ \\
\hline Medical instruments & $0(0.0)$ & 0 \\
\hline Food & $925(86.0)$ & $115(100-200)$ \\
\hline Other & $05(0.5)$ & $200(145-300)$ \\
\hline \multicolumn{3}{|l|}{$\begin{array}{l}\text { Accompanying person } \\
\text { during traveling }\end{array}$} \\
\hline Payment & $0(0.0)$ & 0 \\
\hline Transport & $213(21.5)$ & $100(60-160)$ \\
\hline Food & $77(7.2)$ & $150(100-200)$ \\
\hline Other & $07(0.7)$ & $84(40-100)$ \\
\hline Total & & $120(80-200)$ \\
\hline Total direct cost for a clinic visit & $1075(100.0)$ & $434(200-860)$ \\
\hline
\end{tabular}

(IQR 200-860). The main expenditure for a clinic visit was for drugs (37.4\%) transport (25.9\%) and food (20\%).

\section{Monthly out-of-pocket expenditure}

Median monthly OOP expenditure of the total study population was Rs. 440 (IQR 160-1000) while the entire study population's direct cost was Rs. 1,808,911 during a one month period.

The median monthly out-of-pocket expenditure of a patient on dialysis was Rs. 5940 (IQR 3950-10935). The total OOP incurred by the 38 patients who were on haemodialysis was Rs. 399, 569. This was estimated as $22.1 \%$ (Rs. 399,569/1,808,911) of the total OOP incurred by the total population $(\mathrm{n}=1118)$.

\section{Discussion}

CKD has a significant economic impact on the patients and their families. Sixty four percent of our patients had a personal monthly income less than Rs. 5000 . According to the study done by WHO in 2010 in Padaviya and Madawachchiya divisional secretariat areas, 41.6\% had a monthly income between Rs. 2501 and Rs. 7500 and $16.1 \%$ had a monthly income less than Rs. 2500 [6]. Thus it is evident that the socio-economic situation among CKD patients in Anuradhapura has not improved over the years.

In our study population 59 (5.3\%) patients had been admitted to hospital during the last six months due to kidney disease. Twenty (33.9\%) had paid for medication and $11(18.6 \%)$ had paid for investigations during the hospital stay incurring a median cost of Rs. 1000 (IQR 500-2000) and Rs. 1200 (IQR 850-3000) respectively. Shortages of drugs and reagents for investigations in the public sector is a main reason why patients incur this expenditure. This has been highlighted in several other studies done in Sri Lanka [7,8]. Almost all patients 
(98.3\%) had their immediate family visiting them during the hospital stay and this was the highest cost element during the hospital stay.

In contrast to the findings of the current study, a study done by WHO in 2013, reported lower costs for drugs (median Rs. 200; IQR 90-250), investigations (median Rs. 915; IQR 70-1760) and visiting the patients during the hospital stay (median Rs. 750; IQR 240-2000)(6).

This could be due because the median hospital stay in the WHO study was four days and seven days in the current study. In addition, in the WHO study all study participants were from the Teaching Hospital Anuradhapura while in our study participants had been admitted to different hospitals including Teaching Hospital Anuradhapura and other Divisional and Base hospitals. It is more likely that shortage of drugs and lack of facilities to perform investigations were more in the smaller hospitals, resulting in increased out-of-pocket expenditure.

In our study population 38 (3.4\%) patients were on dialysis at the time of the study. A patient on dialysis spent about Rs. 320 (IQR 320-500) per dialysis episode on transport. Because patients undergo dialysis two to three times a week, traveling is a significant cost to the CKD patients.

OOP for patients on dialysis was Rs. 5490. The total monthly OOP incurred by the 38 haemodialysis patients was $22.1 \%$ of the cost incurred by the total study population. Patients on dialysis have a high symptom burden, psychological distress and the low quality of life. Our findings indicate that these patients also experience a substantial financial burden compared to pre-dialysis patients. This further aggravates their living standards.

The highest expenditure for patients on dialysis was on transport (42.7\%). Cost of travel is based on the distance between home and hospital and the mode of transport. Currently dialysis facilities are only available in Anuradhapura Teaching Hospital and Padaviya Base Hospital. Thus patients in other areas have to travel a fair distance to reach a dialysis facility. This has been reported previously. Kasturiratne et al. found that over $50 \%$ of direct household cost consisted of cost of travel to and from hospital [9].

Almost all patients had attended clinic at least once for their kidney disease during the six months preceding the study. During the clinic visit, $40.1 \%$ had paid for drugs with a median cost of Rs. 460 (IQR 300-800). Seventy six $(7.1 \%)$ had paid for investigations and the median cost was Rs. 800 (IQR 250-1300). These values are much higher than that reported in the WHO study where cost of drugs was Rs. 200 and cost of investigations was Rs. 300(6). This may be because that study was carried out five years before the current study and costs have escalated during this time. Public health services should provide drugs and investigations at no cost, but our results indicate that nearly $50 \%$ of the patients have incurred out-of-pocket expenditure on drugs and investigations.
Among clinic attendees, $37.4 \%$ of the OOP expenditure is for purchase of medication. Among patients attending the psychiatric clinic in the Colombo South Teaching Hospital, the total drug cost was $24 \%$ of the total cost incurred [10]. A study of patients with tuberculosis found that $40 \%$ of expenditure was for drugs and $12 \%$ was for investigations [11]. Preventing shortage of drugs by accurate forecasting can significantly reduce OOP.

In conclusion, CKD patients in Anuradhapura District experienced significant out-of- pocket expenditure due to the disease. The cost was highest in patients on haemodialysis. It is important that the government sponsored social security services identify financially vulnerable groups such as patients on haemodialysis and provide them relief. We recommend that CKD patients be offered low cost transport to access health care services. Hospitals should ensure that all required drugs and investigations are available in the hospitals accessed by patients with CKD.

\section{Conflicts of interest}

There are no conflicts of interest.

\section{References}

1. Alebiosu CO, Ayodele OE. The global burden of chronic kidney disease and the way forward. Ethn Dis 2005; 15: 418.

2. Wanigasuriya K. Aetiological factors of Chronic Kidney Disease in the North Central Province of Sri Lanka: A review of evidence to-date. J Col Com Phy 2012; 26: 17(1).

3. Bommer J. Prevalence and socio-economic aspects of chronic kidney disease. Nephrol Dial Transplant 2002; 17: 8-12.

4. Ministry of Finance. Budget Estimates-2016. Ministry of Finance, 2016 http://www.treasury.gov.lk/images/depts/ $\mathrm{nbd/docs/budgetestimates/2016/approved/eng/}$ bdgtestmates2016E-vol1.pdf (accessed on Feb 14, 2016).

5. Sloan FA, Hsieh C-R. Health economics. 1st ed. London: MIT Press, 2012.

6. World Health Organization. Investigation and Evaluation of Chronic Kidney Disease of Uncertain Aetiology in Sri Lanka. Colombo: World Health Organization, 2013.

7. De Silva A. Economic impacts of mental illness in Caring for the long term mentally ill in the community: Impacts, Needs and Options for Interventions. Colombo: Sahanaya, 2001.

8. Samarasinghe D, Akin J. Report of the Health Strategy Financing Study. Colombo: Ministry of Health and World Bank, 1995.

9. Kasturiratne A. Morbidity pattern and economic burden of non-communicable diseases at tertiary care leve. Thesis for MSc Community Medicine, Post Graduate Institute of Medicine, Colombo; 2003.

10. Attanayake N. Unit cost of treatment for ten selected diseases at public medical institutions in Sri Lanka. Colombo: JICA, 2002.

11. de Silva A, Samarage SM, Somanathan A. Review of Costing Studies Conducted in Sri Lanka - 1990-2004. Colombo: Ministry of Health, 2006. 